\title{
A model of anterior cruciate ligament injury in cynomolgus monkeys developed via arthroscopic surgery
}

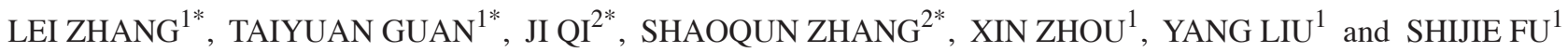 \\ ${ }^{1}$ Department of Orthopedics, The Affiliated T.C.M Hospital of Southwest Medical University, \\ Luzhou, Sichuan 646000; ${ }^{2}$ Department of Orthopedics, School of Traditional Chinese Medicine, \\ Southern Medical University, Guangzhou, Guangdong 510515, P.R. China
}

Received August 4, 2017; Accepted January 5, 2018

DOI: $10.3892 /$ etm.2018.5722

\begin{abstract}
The anterior cruciate ligament (ACL) is an important structure that maintains the stability of knee joints. Animal models of ACL injury are helpful to explore its underlying mechanisms, and strategies for prevention, treatment and rehabilitation. Therefore, the aim of the present study was to develop an efficient model of ACL injury in cynomolgus monkeys via arthroscopic techniques. In the present study, 18 cynomolgus monkeys were randomly divided into a model group $(n=6)$, a sham operation group $(n=6)$ and a blank control group $(n=6)$. One-quarter of the ACL was removed under arthroscopy in the model group. In the sham operation group, only arthroscopic exploration was performed as a control. In the blank control group, monkeys were housed under the same conditions for the same length of time. Magnetic resonance imaging examination was performed pre- and post-operatively, as well as measurements of the circumference of the thigh and calf, and of the maximum flexion degree of the knee. Anterior drawer test, Lachman test and pivot-shift tests were also performed. The results revealed that the injured side of the knees in the model group became unstable, as determined from evaluation of the physical tests. In conclusion, based on these findings, the modeling method of ACL injury was effective, and may contribute to the associated research concerning ACL injury.
\end{abstract}

Correspondence to: Professor Shijie Fu, Department of Orthopedics, The Affiliated T.C.M Hospital of Southwest Medical University, 182 Chun Hui Road, Luzhou, Sichuan 646000, P.R. China E-mail: fushijieggj@126.com

*Contributed equally

Abbreviations: ACL, anterior cruciate ligament; SPF, specific pathogen free; AAALAC, Association for Assessment and Accreditation of Laboratory Animal Care International; PCL, posterior cruciate ligament

Key words: cynomolgus monkeys, anterior cruciate ligament, animal model, arthroscopic, injury

\section{Introduction}

The anterior cruciate ligament (ACL) is among the important structures that maintain the stability of knee joints $(1,2)$. Partial ACL injury and complete ruptures of the ACL are associated with high energy injuries and sports trauma. ACL injury is commonly divided into three types: Mild, moderate and severe injury, According to the severity of the injury. In terms of the severity of injury, conservative treatment or ligament reconstruction can be recommended. Whichever treatment is selected, developing an animal model of ACL injury is one of the effective methods of studying the developmental mechanism, prevention, treatment and rehabilitation of ACL injury.

Severe injury or complete ruptures of the ACL have more impact on the stability of knee joints, and ligament reconstruction is often considered as a clinical treatment (3-8). Injury to one-quarter of the ACL is referred to as a mild injury. In cases of mild injury, if the other ligaments and muscles around the knee joint still maintain the stability of the joint, ligament reconstruction surgery is not necessary, and non-surgical treatment is usually applied. In this aspect, related research using animal models of partial ACL injury are helpful and necessary to improve the efficiency of non-surgical treatments and the recovery from ACL injury.

Many animal models of ACL injury have been reported, some of which have been widely used in related research (9-11). Generally speaking, there is still no suitable animal model that exactly replicates the human knee and ACL injury. On the one hand, it is not easy to develop an ACL injury model in small animals, such as rats, despite the decreased modeling time, as the small size of the knee joint increases the difficulty of surgery and nursing, leading to an increased risk of infection or even accidental death. On the other hand, for some models of large animals such as rabbits and dogs, it is easier to perform surgery due to the larger surgical visual field of the knee joint. However, a longer duration of modeling and rehabilitation are needed, which is costly in terms of experimental funding. In particular, previous studies have been reported that the stifle joints of sheep and the knees of pigs may be more similar to human knees than other animals (such as rats, rabbits or dogs) based on the size and anatomy of the knees $(12,13)$. However, sheep or porcine models are different from humans in terms of their standing physics. By contrast, primates represent valuable 
models for human disease research, since they are phylogenetically close to humans, sharing more similarities in physiology, anatomy and genetics. From previous observations made during feeding of cynomolgus monkeys, it was noted that the monkeys had the ability to stand or walk on their hind limbs alone, and that the length of time spent in such a position was greater compared with the aforementioned animals, thereby showing more similarity with the human body in terms of the physics of standing or walking. These physiological characteristics allow the knee joints of primates to better mimic the human model. Moreover, the instability of the knee joint could be more obvious in the state of standing on hind limbs alone than on four limbs and may, therefore, be more similar to clinical manifestation of ACL injury in humans. Therefore, the ACL injury model of cynomolgus monkeys may be helpful in studying injury and reconstruction of the ACL. However, to date, few studies using an ACL injury in primates have been reported. On the basis of this, the current study mainly focused on modeling ACL injury in cynomolgus monkeys.

Furthermore, the previous methods of developing animal models of ACL injury have mainly involved open surgery, with the risk of blood loss and trauma. With injury to the soft tissues and anatomical structures around knee joint at the time of surgery, rather than injury to the ACL alone, these models are different from common spontaneous sports injury to the ACL in the human body. Besides, these methods may have negative effects on certain follow-up experiments involving structures around the knee joint. Considering aforementioned points, it is necessary to seek a modeling method to overcome these shortcomings. In this aspect, arthroscopic technique could be a better solution. Based on these considerations, we found that the size of the knee joint in monkeys was large enough to operate arthroscopic technique as well, in comparison with other animals.

In this study, we developed a useful alternative model of ACL injury in cynomolgus monkeys via arthroscopic techniques, which may provide a basis for research into ACL injury.

\section{Materials and methods}

Ethical statement. All procedures were approved by the Ethical Inspection Committee of Animal Experiments of Yunnan Yinmore Biological Technology Co., Ltd. (Yunnan, China; no. 2016001). Animal care was in accordance with the 'Guide for the Care and Use of Laboratory Animals' (Office of Science and Health Reports CPRR/NIH 1996).

Experimental animal and feeding. A total of 18 male cynomolgus monkeys (specific pathogen free), were purpose-bred and purchased from Yunnan Yinmore Biological Technology Co., Ltd., with accreditation of the animal research facilities by the Association for Assessment and Accreditation of Laboratory Animal Care (AAALAC).

All monkeys were housed at the Laboratory Animals Breeding Center of Yunnan Yinmore Biological Technology Co., Ltd. In detail, the monkeys were housed in during sleeping, feeding and rest periods in several stable cages, each measuring $1.5 \mathrm{~m}(\mathrm{H}) \times 2 \mathrm{~m}(\mathrm{~W}) \times 1.5 \mathrm{~m}(\mathrm{D})$. The housing conditions were a 12/12-h light/dark cycle, with a temperature of $22-24^{\circ} \mathrm{C}$ and relative humidity of $45-65 \%$. The monkeys were fed daily with formula feeds. Water was available ad libitum via water bottles. Additionally, all animals were moved out of the cages to another spacious activity room, approximately measuring $4 \mathrm{~m}(\mathrm{H}) \times 12.5 \mathrm{~m}(\mathrm{~W}) \times 8 \mathrm{~m}(\mathrm{D})$, equipped with resting shelves, a small rockery, wooden branches and a swing, for 6-8 h of free time per day. Additionally, videos and music were occasionally played to relax the monkeys as well. (Fig. 1A and B).

Animal modeling. The animals were randomly divided into three groups, including a model group $(n=6)$, a sham operation group $(n=6)$, and a blank control group $(n=6)$. Based on previous experiments and related statistical estimations, the sample size of 6 per group can be statistically significant, especially for experiments on primates, such as cynomolgus monkeys. In the model group and the sham operation group, the unilateral side of injury was chosen at random for each animal.

Cynomolgus monkeys in the model group were subjected to unilateral knee surgery to induce ACL injury. The arthroscopic instruments (Smith \& Nephew Endoscopy, Andover, MA, USA; 72200616) were prepared before surgery and the equipment was strictly sterilized by the operators. Then, the monkeys were anesthetized using Zoletil 50 (Virbac, Carros, France; $5 \mathrm{mg} / \mathrm{kg}$, intramuscular) and were fixed in a supine position with the surgical area shaved. Marking of the incision and the application of an ipsilateral lower extremity proximal tourniquet was performed. After all the preparatory steps, anterior medial and anterior lateral approaches of the knee joint were built with $0.5-\mathrm{cm}$ long incisions to explore the knee joint (Fig. 2A and B). Exploration indicated that the articular cartilage, ACL, posterior cruciate ligament (PCL) and meniscus were intact. Approximately, one-quarter of the ACL was transversely cut (Fig. 2C and D) under a clear arthroscopic field of vision. At the end of the surgery, the incision was closed with 3-0 absorbable sutures (Alcon Laboratories, Inc., Fort Worth, TX, USA). The operation finished. The modeling operation was completed by the same group of doctors. Soft padded bandages were placed and maintained on the operated limbs for 2 weeks. For the first 3 postoperative days, levofloxacin hydrochloride and sodium chloride injection (Heng Ao, Shanghai, China; $8 \mathrm{mg} / \mathrm{kg}$, one dose $/ 12 \mathrm{~h}$, intravenous) were used to prevent infection. The animals were monitored daily and tramadol hydrochloride for injections (QiMaiTe, Shijiazhuang, China; $2 \mathrm{mg} / \mathrm{kg}$, one dose/day, intramuscular) were used to provide analgesia as needed.

In the sham operation group, all preoperative preparation and postoperative care was the same as the model group, while only arthroscopic exploration was performed without any interventions.

As a control, cynomolgus monkeys in the blank group underwent normal feeding without any interventions.

\section{Model identification}

Magnetic resonance imaging (MRI). The MRI (Multiva 1.5T; Philips Healthcare, Amsterdam, The Netherlands) inspection of the knees of the monkeys in the three groups was performed by the same radiologist, under anesthesia, before surgery and at 2 weeks post-surgery. 

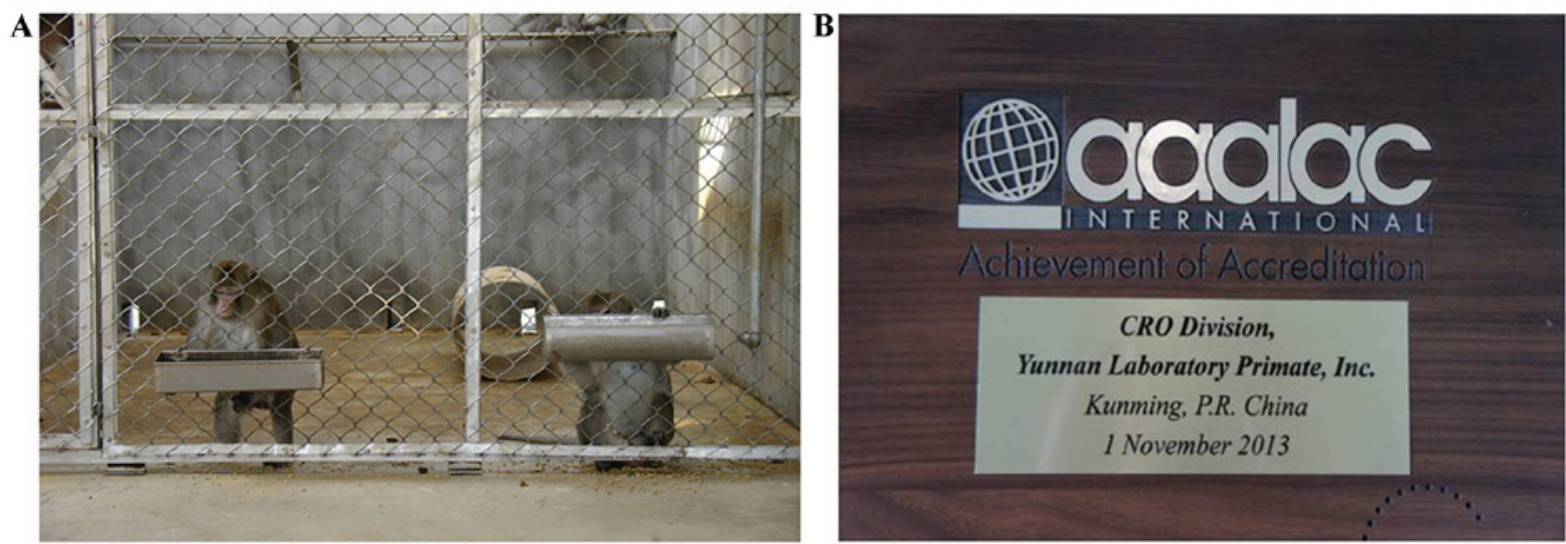

Figure 1. Daily activity conditions of cynomolgus monkeys and the Association for Assessment and Accreditation of Laboratory Animal Care International (AAALAC) accreditation. (A) The monkeys were housed in several stable cages during periods of sleeping, feeding and rest. Additionally, all animals were moved out of the cages to another spacious activity room, equipped with resting shelves, a small rockery, wooden branches and a swing, for 6-8 $\mathrm{h}$ of free time per day. (B) Accreditation of the animal research facilities by the AAALAC.
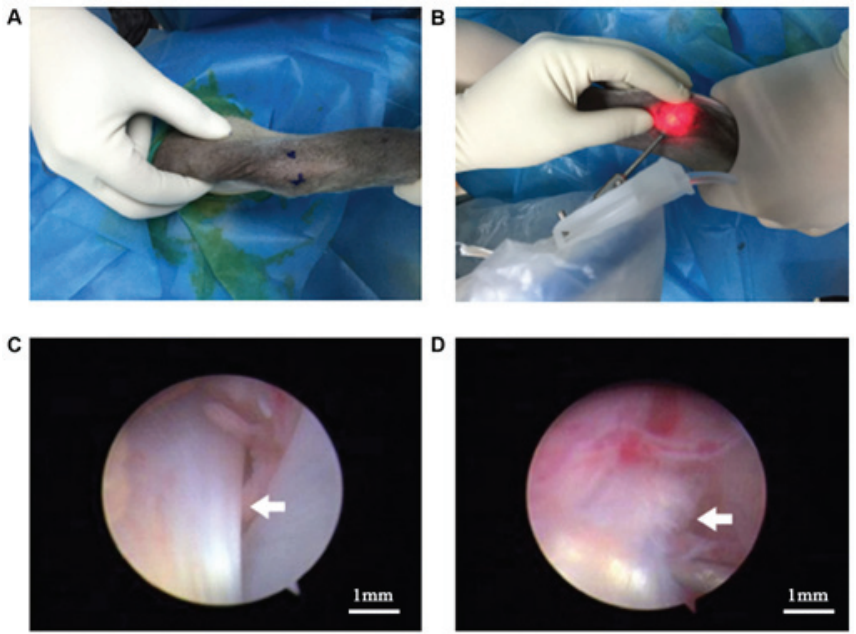

Figure 2. Development of animal models under arthroscopy. (A) Marking the incision for arthroscopic approaches before surgery; (B) after all preparations, the anterior medial and anterior lateral approaches of the knee joint were performed with $0.5-\mathrm{cm}$ long incisions to explore the knee joint, via arthroscopy in the cavity of the knee; (C) exploration indicated that the articular cartilage, anterior cruciate ligament (ACL), posterior cruciate ligament and meniscus were intact, specifically, the normal and smooth ACL was observed under arthroscopy, the white arrow pointed to the normal ACL; (D) One-quarter of the ACL was transversely cut using a hook knife under a clear arthroscopic visual field, the white arrow pointed to the injured ACL.

Observation of animal physiology. Before surgery, measurement of the circumference of the thigh and calf, and of the maximum flexion degree of the knee, as well as Anterior drawer, Lachman and Pivot-shift tests, were performed on monkeys in the three groups under anesthesia, by the same orthopedist specializing in surgery and recovery of the knees. At 2 weeks post-surgery, when the incision had healed and tissue edema had disappeared, these measurements were performed again in the three groups.

Measurement of bilateral thigh and calf circumference. Thigh circumference was measured at $5 \mathrm{~cm}$ above the patella (Fig. 3A). Usually, the thigh circumference of humans is measured at the suprapatellar $10-15 \mathrm{~cm}$ point. Because the thigh segment of the cynomolgus monkey is shorter than that of humans, thigh circumference was tested at $5 \mathrm{~cm}$ above the patella on the monkeys. In addition, calf circumference was measured at approximately the widest position of the calf (Fig. 3B). The measurements were helpful to compare the degree of muscular atrophy before and after surgery.

Maximum flexion degree of the knee. Under anesthesia, the position of the knee joint was flexed maximally in the supine position, and the angle (Fig. 3C) was measured. The measurement was helpful to compare the motion of the knee joint before and after surgery.

Anterior drawer test. Under anesthesia, monkeys were fixed in a supine position, with the hips passively flexed to 45 degrees, the knee passively flexed to 90 degrees and the feet flat on the table. With the distal side of the leg fixed, the proximal side of the leg was pulled forward by the examiner using both hands, and the degree of movement of the tibia was scored as follows (Fig. 3D): (-), double tibial forward movement was equal; (1+), the ipsilateral tibial migration was greater than the healthy side and tibial forward movement was $<5 \mathrm{~mm}$; (2+), tibial forward movement was $5-10 \mathrm{~mm}$; (3+), tibial forward movement was $>10 \mathrm{~mm}$. In the clinic, (-) indicates that the stability of the ipsilateral knee joint is normal. Meanwhile, other scores indicate that the ipsilateral knee joint is unstable, and higher scores indicate greater instability.

Lachman test. The distal side of the leg was held in one hand and the proximal side of the calf was held in the other hand under anesthesia in a supine position, so as to observe the movement by reverse force of both hands (Fig. 3E). The scoring system was the same as for the anterior drawer test.

Pivot-shift test. In a supine position, monkeys were anesthetized before inspection with a fully-extended knee joint. One hand of the examiner was placed on the outside of the knee, with the other holding the foot to make the calf rotate. The knee was gradually flexed from 0 degrees, and the tibial plateau began to gradually move forward towards subluxation when the knee was moved from the 'lock' position. When the knee was flexed 

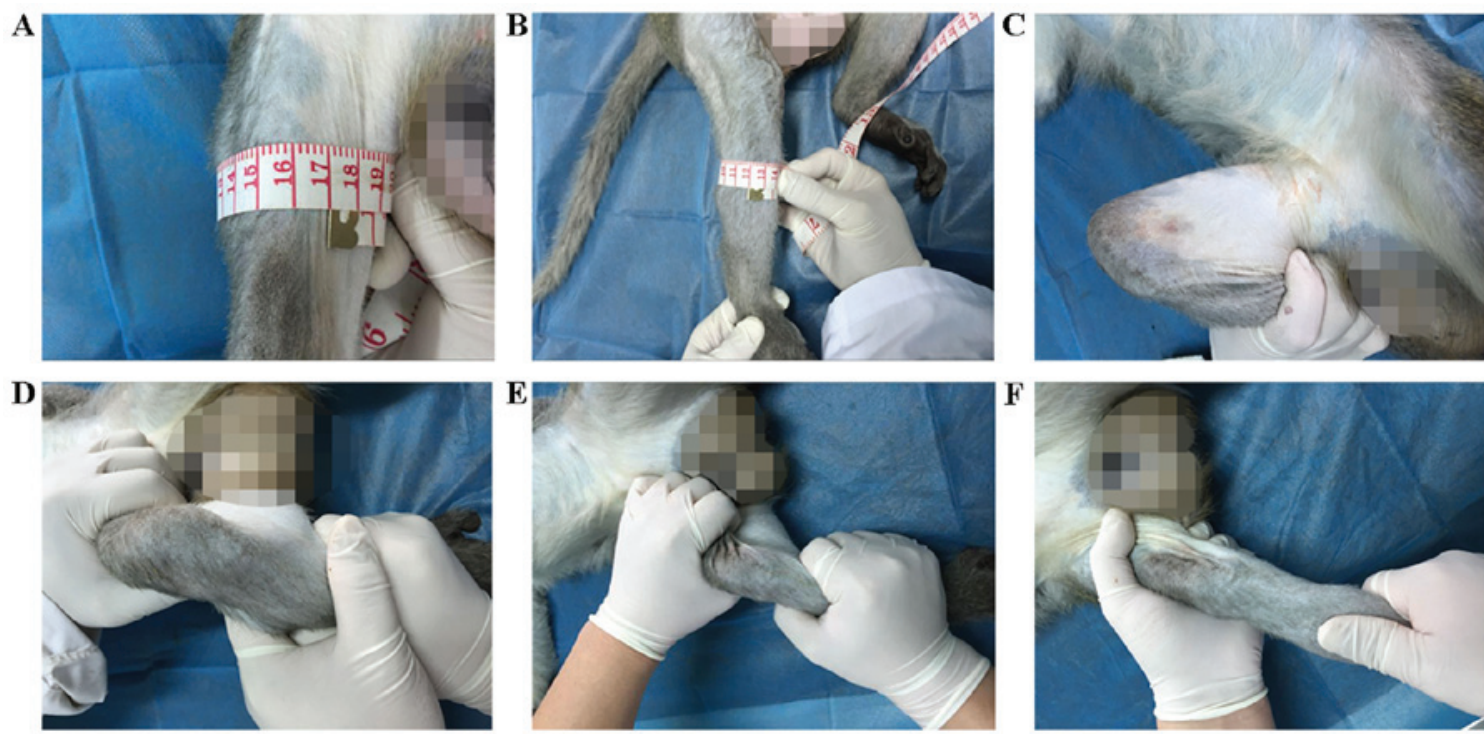

Figure 3. Observation of animal physiology. (A) Measurement of the circumference of the thigh. The thigh circumference of humans is usually measured at the suprapatellar 10-15 cm point. As the thigh segment of the cynomolgus monkeys is shorter than that of humans, thigh circumference was tested at 5 cm above the patella on the monkeys. (B) Measurement of the circumference of the calf. Calf circumference was measured at the widest position on the calf (C) Measurement of the maximum flexion degree of the knee. In the state of anesthesia, the position of the knee joint was flexed maximally in the supine position, and the angle was measured. (D) Evaluation of the anterior drawer test. Under anesthesia, monkeys were fixed in a supine position, with the hips passively flexed to 45 degrees, the knee passively flexed to 90 degrees and the feet flat on the table. With the distal side of the leg fixed, the proximal side of the leg was pulled forward by the examiner using both hands, and the degree of movement of the tibia was observed. (E) Evaluation of the Lachman test. The distal side of the leg was held in one hand and the proximal side of the calf was held with the other under anesthesia in a supine position, so as to observe the movement by reverse force of both hands. (F) Evaluation of the pivot-shift test. In a supine position, monkeys were anesthetized before inspection with full extension of the knee joint. One hand of the examiner was placed on the outside of the knee, and the other held the foot to make the calf rotate. The knee was gradually flexed from 0 degrees, and the tibial plateau began to gradually move forward toward subluxation when the knee was removed from the 'lock' position. When the knee was flexed to 20 degrees, instability appeared as a positive result.

to 20 degrees, instability appeared as a positive result (Fig. 3F). A positive result indicated instability of the knee joint.

At the end of above evaluation, all cynomolgus monkeys were fed continually as usual, in preparation for future studies into ACL injury and other related research.

Statistical methods. All data were statistically analyzed using SPSS 17.0 (SPSS, Inc., Chicago, IL, USA) statistical software. All measurement data are expressed as the mean \pm standard deviation. One way analysis of variance was used to compare differences among the three groups in preoperative or postoperative indexes. Comparisons were performed, by paired t-test and Levene's test, between the preoperative and postoperative indexes of the same group. The non-parametric Kruskal-Wallis $\mathrm{H}$ test and the $\chi^{2}$ test were performed for comparison of ranked data among the three groups. The level of statistical significance was set at $\alpha=0.05$.

\section{Results}

Animal status. At 2 weeks post-surgery, the incisions had healed without any infection or delayed healing in the monkeys of the model and sham operation groups. The operated limbs were able to be exercised gradually. At the same time, the monkeys in the blank control group remained healthy without any injury.

MRI. Before the operation, all animals were examined with MRI and no abnormalities were found. The MRI inspection of the knee joint in the model group showed that the ACL had some signs of injury, while the articular cartilage, PCL and meniscus were intact (Fig. 4A). In the sham operation group and the blank control group, MRI analysis indicated that the basic anatomical structures of the knee joint, including the articular cartilage, ACL, PCL and meniscus, were intact (Fig. 4B).

Observation of animal physiology. Before the operation, no significant differences were observed among the three groups regarding age, weight, head-sacrum length, circumference of the thigh and calf, maximum flexion degree of the knee, and anterior drawer test, Lachman test and pivot-shift test results (Table I).

There were no significant differences among the three groups on examination of the circumference of the thigh and calf, and the maximum flexion degree of the knee after surgery (Table I). By contrast, in the postoperative evaluations of the anterior drawer, Lachman and pivot-shift tests, significant differences were noted among the three groups, while no significant differences were found between the sham operation and the blank control groups (Table II).

No significant differences were observed between the sham operation group and the blank control group regarding the physical evaluations performed before and after surgery (Table II).

In the model group, the differences in the anterior drawer test, Lachman test and pivot-shift test results were significant between the preoperative and postoperative evaluations (Table III). No significant differences were identified between the preoperative and postoperative evaluations of the 

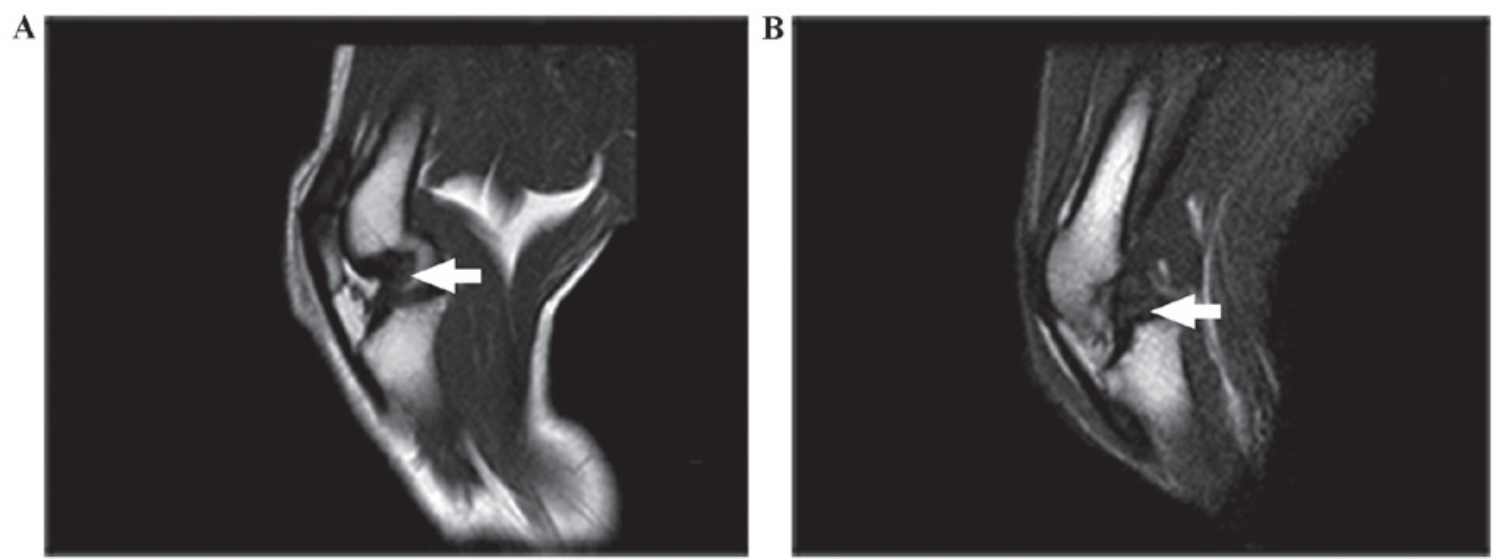

Figure 4. Magnetic resonance imaging observation of the knee joints. (A) The normal ACL on T1W was continuous and uniform, and the tension was good. (B) Tension and continuity of the injured ACL on T1W were poor. ACL, anterior cruciate ligament; T1W, T1-weighted.

circumference of the thigh and calf, and the maximum flexion degree of the knee.

\section{Discussion}

There is no definite classification for ACL injuries, Ihara and Kawano (14) classified MRI of the ACL in the sagittal plan into 4 types according to the degree of injury: Type I, straight and continuous band; type II, curved and continuous band; type III, displacement; and type IV, disrupted or horizontally oriented or unclear. American Academy of Orthopaedic Surgeons (AAOS) considered the injured ligaments as 'sprains' and the ACL injuries are graded on a severity scale: Grade 1 Sprains. The ligament is mildly damaged, it has been slightly stretched, but is still able to help keep the knee joint stable. Grade 2 Sprains. A Grade 2 Sprain stretches the ligament to the point where it becomes loose, this is often referred to as a partial tear of the ligament. Grade 3 Sprains. This type of sprain is most commonly referred to as a complete tear of the ligament, the ligament has been split into two pieces, and the knee joint is unstable. It is known that the injured ACL has the potential for primary healing, and several studies have reported a spontaneous healing of the ACL after acute rupture (15-17). Also, according to AAOS, nonsurgical management of isolated ACL tears is likely to be successful or may be indicated in patients with partial tears and no instability symptoms. Whereas, there is a limitation for doctors to identify the mild injury, and it would result in worse outcome if the patients missed the proper treatments. Partial tears take up 10 to $35 \%$ of ACL lesions, which are more or less serious lesions with a variable prognosis $(18,19)$. The treatment of choice for partial ACL tears remains ambiguous. Traditionally, there are two treatments for partial tears: surgical treatments which require sacrifice of the remnant ACL fiber for proper graft placement, whereas nonsurgical treatments are suitable for patients who do not participate in strenuous sports activities $(20,21)$. Besides, recently, selective ACL augmentation has been considered as an alternative choice of treatment $(22,23)$, as it can preserve knee joint proprioception (24). Whereas the biological and biomechanical advantages of the augmentation have not been fully investigated (25). Several comparative studies have compared augmentation with classical ACL reconstruction and got unlike outcomes (26-28). Thus, it is necessary to create models for studying the mild injury. And one-quarter ACL injury is an ideal tear type that not only represents for partial tear but also minimizes the injuries to model animals.

In MRI analysis, the degree and range of injury of the ACL may be displayed (29-31), although the MRI signal of the ACL may be uneven, due to the occurrence of natural degeneration of the ACL (32-34). As a result, it is easy to misdiagnose ACL injury via MRI. Therefore, MRI can only be used as an objective auxiliary examination of ACL injury and must be confirmed with arthroscopy. In our study, the model was evaluated after 2 weeks, mainly because tissues around the knee joint that had been injured in the operation would have recovered, and edema would have dissipated. Comparisons between the functional evaluations of the knee joint were performed among the three groups, as well as preoperative and postoperative evaluation in the model group alone. Statistical differences were found in the evaluations of the anterior drawer test, Lachman test and pivot-shift test (35-37), while no significant differences in the maximum flexion degree of the knee, and the circumference of the thigh and calf, were observed. The results indicated that one-quarter ACL injury may cause instability of the knee joint when ligaments and muscles around the knee joint do not compensate to maintain the stability of the joint (38-41), which reflected the main characteristics of the model. At the same time, it is notable that short-term instability of knee will not lead to atrophy of the muscles of the hind limb and decreased flexion of the knee. Moreover, in the sham operation and the blank control groups, no statistical differences were observed regarding the physiological tests performed before and after intervention, excluding the effects of objective conditions on the development of model, making the results more convincing.

The cynomolgus monkey ACL injury model has certain advantages (42). Firstly, compared with other experimental animals, cynomolgus monkeys are more similar to human beings in the anatomical structure of the knee joints, such as the femoral condyle, tibial plateau, patella, patellar tendons, ACL, PCL, and medial and lateral meniscus. Secondly, the instability of the knee joint after ACL injury in monkeys is more similar to the common manifestation of ACL injury in humans, as a result of similar standing physics. 
Table I. Baseline characteristics of cynomolgus monkeys prior to surgery.

\begin{tabular}{lcrr}
\hline & & $\begin{array}{c}\text { Sham operation } \\
\text { group }(\mathrm{n}=6)\end{array}$ & $\begin{array}{c}\text { Blank control } \\
\text { group }(\mathrm{n}=6)\end{array}$ \\
\hline Parameter & Model group $(\mathrm{n}=6)$ & $4.62 \pm 0.10$ & $4.62 \pm 0.13$ \\
Weight (kg) & $4.62 \pm 0.12$ & $6.52 \pm 0.18$ & $6.49 \pm 0.47$ \\
Head-sacrum length $(\mathrm{m})$ & $6.55 \pm 0.21$ & $0.43 \pm 0.22$ & $0.42 \pm 0.18$ \\
Thigh circumference $(\mathrm{cm})$ & $0.42 \pm 0.19$ & $16.82 \pm 0.16$ & $16.87 \pm 0.32$ \\
Calf circumference $(\mathrm{cm})$ & $16.85 \pm 0.31$ & $12.00 \pm 0.26$ & $12.03 \pm 0.41$ \\
Maximum flexion degree of knee $\left(^{\circ}\right)$ & $12.03 \pm 0.34$ & $156.50 \pm 5.54$ & $156.50 \pm 3.02$ \\
Anterior drawer & $157.00 \pm 5.10$ & $(-)(\mathrm{n}=6)$ & $(-)(\mathrm{n}=6)$ \\
Lachman & $(-)(\mathrm{n}=6)$ & $(-)(\mathrm{n}=6)$ & $(-)(\mathrm{n}=6)$ \\
Pivot-shift & $(-)(\mathrm{n}=6)$ & $(-)(\mathrm{n}=6)$ & $(-)(\mathrm{n}=6)$ \\
\hline
\end{tabular}

Data are presented as the mean \pm standard deviation.

Table II. Comparison between the characteristics prior to and following surgery in cynomolgus monkeys.

\begin{tabular}{llccc}
\hline Group & \multicolumn{1}{c}{ Time } & $\begin{array}{c}\text { Thigh } \\
\text { circumference }(\mathrm{cm})\end{array}$ & $\begin{array}{c}\text { Calf } \\
\text { circumference }(\mathrm{cm})\end{array}$ & $\begin{array}{c}\text { Maximum flexion } \\
\text { degree of knee }\left({ }^{\circ}\right)\end{array}$ \\
\hline Model group $(\mathrm{n}=6)$ & Preoperation & $16.85 \pm 0.31$ & $12.03 \pm 0.34$ & $157.00 \pm 5.10$ \\
& Postoperation & $16.78 \pm 0.27$ & $12.30 \pm 0.34$ & $156.00 \pm 1.46$ \\
Sham operation group $(\mathrm{n}=6)$ & Preoperation & $16.82 \pm 0.16$ & $12.00 \pm 0.26$ & $11.92 \pm 0.87$ \\
& Postoperation & $16.82 \pm 0.16$ & $12.03 \pm 0.41$ & $156.17 \pm 2.20$ \\
Blank control group $(\mathrm{n}=6)$ & Preoperation & $16.87 \pm 0.32$ & $11.90 \pm 0.49$ & $156.50 \pm 3.02$ \\
& Postoperation & $16.88 \pm 0.24$ & $156.00 \pm 1.29$ \\
\hline
\end{tabular}

Data are presented as the mean \pm standard deviation.

Table III. Comparison of physical examinations prior to and following surgery in cynomolgus monkeys.

\begin{tabular}{|c|c|c|c|c|}
\hline Group & Time & Anterior drawer test & Lachman test & Pivot-shift test \\
\hline \multirow[t]{2}{*}{ Model group (n=6) } & Preoperation & $(-)(n=6)$ & $(-)(n=6)$ & $(-)(n=6)$ \\
\hline & Postoperation & $(2+)(n=5),(3+)(n=1)^{a-c}$ & $(2+)(\mathrm{n}=3),(3+)(\mathrm{n}=3)^{\mathrm{a}-\mathrm{c}}$ & $(+)(\mathrm{n}=6)^{\mathrm{a}-\mathrm{c}}$ \\
\hline \multirow[t]{2}{*}{ Sham operation group $(n=6)$} & Preoperation & $0+(n=6)$ & $0+(n=6)$ & $(-)(n=6)$ \\
\hline & Postoperation & $0+(n=6)$ & $0+(n=6)$ & $(-)(n=6)$ \\
\hline \multirow[t]{2}{*}{ Blank control group $(n=6)$} & Preoperation & $0+(n=6)$ & $0+(n=6)$ & $(-)(n=6)$ \\
\hline & Postoperation & $0+(n=6)$ & $0+(n=6)$ & $(-)(n=6)$ \\
\hline
\end{tabular}

Data are presented as the mean \pm standard deviation. ${ }^{\mathrm{a}} \mathrm{P}<0.05$ vs. model group (preoperation); ${ }^{\mathrm{b}} \mathrm{P}<0.05$ vs. sham operation group (postoperation); ${ }^{\mathrm{P}}<0.05$ vs. blank control group (postoperation).

For instance, the knee joints of the cynomolgus monkeys often bear vertical weight through standing on the hind limbs during daily activities. The length of time that the cynomolgus monkey spends standing vertically or squatting is more similar to humans, compared with other model animals, indicating similar biomechanical characteristics. Thirdly, the size of the articular cavity is acceptable for the arthroscopic lens $(2.7 \mathrm{~mm})$, allowing for modeling by arthroscopy in this study.
In addition, this method of modeling is a short-duration operation with minimal invasive surgical injury. Animals were operated on under strict sterile procedures, and surgery was performed by a qualified surgeon during the process of modeling. The lack of any infection indicated that primates, such as cynomolgus monkeys, may have a strong immune system, which is conducive to an enhanced success rate of modeling. Simultaneously, this reduces any interference of infection in the modeling process. The whole modeling 
process was conducive to the rapid development of a model with fast recovery and fewer adverse effects. Therefore, this model of ACL injury is more similar to human ACL injury, which may indicate its greater suitability, compared with other animals, for basic research and clinical applications.

Arthroscopic techniques have been successfully applied in many clinical disciplines $(43,44)$. In terms of joint surgery, arthroscopy has been widely used in the shoulder, elbow, wrist, hip, knee, ankle and other joints (45-50), especially in applications in the knee joint, and the technology has progressed (51-57). As a result, arthroscopic techniques were selected to develop the present model, due a series of advantages. Firstly, compared with other modeling methods of open surgery, the surgical trauma is limited and the surgical skin incision is only $0.5 \mathrm{~cm}$ in length, leading to rapid postoperative healing without other injuries or complications. This can effectively ensure the simplicity of the model and reduce confounds to the experimental results. Secondly, the small amount of intraoperative bleeding reduces the risk of postoperative complications, such as blood accumulation in the joint, infection, inflammation and tissue adhesion after surgery. Thirdly, arthroscopic techniques have the characteristic of enhanced visibility in the joint cavity, reducing damage to surrounding tissues and structures, so as to allow for quantification and precision regarding damage to the ACL. Finally, under arthroscopy, the tissue (joint fluid, ligaments, synovial membrane and cartilage) in the joint cavity can be analyzed via dynamic monitoring.

Despite the efficiency of the model obtained in this study, certain limitations remained. Primarily, all of the cynomolgus monkeys were male and there was, therefore, uncertainty about the additional effects of gender on the results. In addition, the model was evaluated at 2 weeks post-surgery, so there was a lack of long term follow-up regarding the effects of the arthroscopic surgery. The evaluation criteria of the animal model could be more in-depth. In addition, the study did not include pathological staining, immunohistochemistry or any other follow-up observation of the ACL, and microscopic changes in the ACL due to injury were not observed. All of these considerations remain to be addressed in future studies.

In conclusion, the cynomolgus monkey model of ACL injury, with the main feature of instability of the knee joint, provides an important tool for basic research into ACL. Using the arthroscopic technique, a method associated with little surgical trauma and a short surgical and recovery duration, the aim of quantitative and accurate ACL injury can be achieved. This model may be helpful for basic research in this field.

\section{References}

1. McHugh MP, Tyler TF, Nicholas SJ, Browne MG and Gleim GW: Electromyographic analysis of quadriceps fatigue after anterior cruciate ligament reconstruction. J Orthop Sports Phys Ther 31: 25-32, 2001.

2. Rahnemai-Azar AA, Sabzevari S, Irarrázaval S, Chao T and Fu FH: Anatomical individualized ACL reconstruction. Arch Bone Jt Surg 4: 291-297, 2016.

3. Fanlli GC, Orcutt DR and Edson CJ: The multiple-ligament injured knee: Evaluation, treatment, and results. Arthroscopy 21: 471-486, 2005

4. Poehling GG, Curl WW, Lee CA, Ginn TA, Rushing JT, Naughton MJ, Holden MB, Martin DF and Smith BP: Analysis of outcomes of anterior cructate ligament repair with 5-year follw up: Allograft versus autograft. Arthroscopy 21: 774-785, 2005.
5. Almqvist KF, Willaert $\mathrm{P}$, De Brabandere $\mathrm{S}$, Criel $\mathrm{K}$ and Verdonk R: A long-term study of anterior cruciate ligament allograft reconstruction. Knee Surg Sports Traumatol Arthrosc 17: 818-822, 2009

6. Xie X, Liu X, Chen Z, Yu Y, Peng S and Li Q: A meta-analysis of bone-patellar tendon-bone autograft versus four-strand hamstring tendon autograft for anterior cruciate ligament reconstruction. Knee 22: 100-110, 2015

7. Calvo R, Figueroa D, Gili F, Vaisman A, Mocoçain P, Espinosa M, Espinosa M, León A and Arellano S: Transphyseal anterior cruciate ligament reconstruction in patients with open physes: 10-year follow-up study. Am J Sports Med 43: 289-294, 2015.

8. Sonnery-Cottet B, Thaunat M, Freychet B, Pupim BH, Murphy CG and Claes S: Outcome of a combined anterior cruciate ligament and anterolateral ligament reconstruction technique with a minimum 2-year follow-up. Am J Sports Med 43: 1598-1605, 2015

9. Kiapour AM, Shalvoy MR, Murray MM and Fleming BC: Validation of porcine knee as a sex-specific model to study human anterior cruciate ligament disorders. Clin Orthop Relat Res 473: 639-650, 2015.

10. Maerz T, Kurdziel MD, Davidson AA, Baker KC, Anderson K and Matthew HW: Biomechanical characterization of a model of noninvasive, traumatic anterior cruciate ligament injury in the rat. Ann Biomed Eng 43: 2467-2476, 2015.

11. Kiapour AM, Fleming BC, Proffen BL and Murray MM: Sex influences the biomechanical outcomes of anterior cruciate ligament reconstruction in a pre-clinical large animal model. Am J Sports Med 43: 1623-1631, 2015.

12. Proffen BL, McElfresh M, Fleming BC and Murray MM: A comparative anatomical study of the human knee and six animal species. Knee 19: 493-499, 2012.

13. Madry H, Ochi M, Cucchiarini M, Pape D and Seil R: Large animal models in experimental knee sports surgery: Focus on clinical translation. J Exp Orthop 2: 9, 2015.

14. Ihara $\mathrm{H}$ and Kawano $\mathrm{T}$ : Influence of age on healing capacity of acute tears of the anterior cruciate ligament based on magnetic resonance imaging assessment. J Comput Assist Tomogr 41: 206-211, 2017.

15. Fujimoto E, Sumen Y, Ochi M and Ikuta Y: Spontaneous healing of acute anterior cruciate ligament (ACL) injuries-conservative treatment using an extension block soft brace without anterior stabilization. Arch Orthop Trauma Surg 122: 212-216, 2002.

16. Ihara H, Miwa M, Deya K and Torisu K: MRI of anterior cruciate ligament healing. J Comput Assist Tomogr 20: 317-321, 1996.

17. Kurosaka M, Yoshiya S, Mizuno T and Mizuno K: Spontaneous healing of a tear of the anterior cruciate ligament: A report of two cases. J Bone Joint Surg Am 80: 1200-1203, 1998.

18. Guenoun D, Le Corroller T, Amous Z, Pauly V, Sbihi A and Champsaur P: The contribution of MRI to the diagnosis of traumatic tears of the anterior cruciate ligament. Diagn Interv Imaging 93: 331-341, 2012.

19. Donell ST, Marshall TJ, Darrah C and Shepstone L: Cruciate ligament assessment in MRI scans: A pilot study of a static drawer technique. Knee 13: 137-144, 2006.

20. Bak K, Scavenius M, Hansen S, Nørring K, Jensen KH and Jørgensen U: Isolated partial rupture of the anterior cruciate ligament: Long-term follow-up of 56 cases. Knee Surg Sports Traumatol Arthrose 5: 66-71, 1997.

21. Noyes FR, Mooar LA, Moorman CT III and McGinniss GH: Partial tears of the anterior cruciate ligament: Progression to complete ligament deficiency. J Bone Joint Surg Br 71: 825-833, 1989.

22. Dienst M, Burks RT and Greis PE: Anatomy and biomechanics of the anterior cruciate ligament. Orthop Clin North Am 33: 605-620, v, 2002

23. Duthon VB, Barea C, Abrassart S, Fasel JH, Fritschy D and Ménétrey J: Anatomy of the anterior cruciate ligament. Knee Surg Sports Traumatol Arthrosc 14: 204-213, 2006.

24. Buda R, Ferruzzi A, Vannini F, Zambelli L and Di Caprio F: Augmentation technique with semitendinosus and gracilis tendons in chronic partial lesions of the ACL: Clinical and arthrometric analysis. Knee Surg Sports Traumatol Arthrosc 14: 1101-1107, 2006.

25. Mifune Y, Ota S, Takayama K, Hoshino Y, Matsumoto T, Kuroda R, Kurosaka M, Fu FH and Huard J: Therapeutic advantage in selective ligament augmentation for partial tears of the anterior cruciate ligament: Results in an animal model. Am J Sports Med 41: 365-373, 2013. 
26. Serrano-Fernandez JM, Espejo-Baena A, Martin-Castilla B, De La Torre-Solis F, Mariscal-Lara J and Merino-Ruiz ML: Augmentation technique for partial ACL ruptures using semitendinosus tendon in the over-the-top position. Knee Surg Sports Traumatol Arthrose 18: 1214-1218, 2010.

27. Demirağ B, Ermutlu C, Aydemir F and Durak K: A comparison of clinical outcome of augmentation and standard reconstruction techniques for partial anterior cruciate ligament tears. Eklem Hastalik Cerrahisi 23: 140-144, 2012.

28. Maestro A, Suárez-Suárez MA, Rodríguez-López L and Villa-Vigil A: Stability evaluation after isolated reconstruction of anteromedial or posterolateral bundle in symptomatic partial tears of anterior cruciate ligament. Eur J Orthop Surg Traumatol 23: 471-480, 2013

29. Vahey TN, Broome DR, Kayes KJ and Shelbourne KD: Acute and chronic tears of the anterior cruciate ligament: Differential features at MR imaging. Radiology 181: 251-253, 1991.

30. Moore SL: Imaging the anterior cruciate ligament. Orthop Clin North Am 33: 663-674, 2002.

31. Lee K, Siegel MJ, Lau DM, Hildebolt CF and Matava MJ: Anterior cruciate ligament tears: MR imaging-based diagnosis in a pediatric population. Radiology 213: 697-704, 1999.

32. Cushner FD, La Rosa DF, Vigorita VJ, Scuderi GR, Scott WN and Insall JN: A quantitative histologic comparison: ACL degeneration in the osteoarthritic knee. J Arthroplasty 18: 687-692, 2003.

33. Zou YC, Chen LH, Ye YL, Yang GG, Mao Z, Liu DD, Chen JQ, Chen JJ and Liu G: Attenuated synovial fluid ghrelin levels are linked with cartilage damage, meniscus injury, and clinical symptoms in patients with knee anterior cruciate ligament deficiency. Discov Med 22: 325-335, 2016.

34. Pedoia V, Su F, Amano K, Li Q, McCulloch CE, Souza RB, Link TM, Ma BC and Li X: Analysis of the articular cartilage $\mathrm{T} 1 \mathrm{O}$ and $\mathrm{T} 2$ relaxation times changes after ACL reconstruction in injured and contralateral knees and relationships with bone shape. J Orthop Res 35: 707-717, 2017.

35. Kartus J, Movin T and Karlsson J: Donor-site morbidity and anterior knee problems after anterior cruciate ligament reconstruction using autografts. Arthroscopy 17: 971-980, 2001.

36. Adachi N, Ochi M, Uchio Y, Sakai Y, Kuriwaka M and Fujihara A: Harvesting hamstring tendons for ACL reconstruction influences postoperative hamstring muscle performance. Arch Orthop Trauma Surg 123: 460-465, 2003.

37. Choi NH, Yang BS and Victoroff BN: Clinical and radiological outcomes after hamstring anterior cruciate ligament reconstructions: Comparison between fixed-loop and adjustable-loop cortical suspension devices. Am J Sports Med 45: 826-831, 2017.

38. Boeth H, Duda GN, Heller MO, Ehrig RM, Doyscher R, Jung T, Moewis P, Scheffler S and Taylor WR: Anterior cruciate ligament-deficient patients with passive knee joint laxity have a decreased range of anterior-posterior motion during active movements. Am J Sports Med 41: 1051-1057, 2013.

39. Mather RC III, Koenig L, Kocher MS, Dall TM, Gallo P, Scott DJ, Bach BR Jr and Spindler KP; MOON Knee Group: Societal and economic impact of anterior cruciate ligament tears. J Bone Joint Surg Am 95: 1751-1759, 2013.

40. Bohn MB, Petersen AK, Nielsen DB, Sørensen H and Lind M: Three-dimensional kinematic and kinetic analysis of knee rotational stability in ACL-deficient patients during walking, running and pivoting. J Exp Orthop 3: 27, 2016.

41. Goetz J, Schiessl S, Baier C, Dullien S, Mueller K, Grifka J and Koeck F: Postural stability after patient-specific interpositional knee spacer or total knee arthroplasty: A comparative study. Int Orthop 41: 67-73, 2017.

42. Fisher MB, Liang R, Jung HJ, Kim KE, Zamarra G, Almarza AJ, McMahon PJ and Woo SL: Potential of healing a transected anterior cruciate ligament with genetically modified extracellular matrix bioscaffolds in a goat model. Knee Surg Sports Traumatol Arthrosc 20: 1357-1365, 2012
43. Aglietti P, Zaccherotti G, Menchetti PP and De Biase P: A comparison of clinical and radiological parameters with two arthroscopic techniques for anterior cruciate ligament reconstruction. Knee Surg Sports Traumatol Arthrosc 3: 2-8, 1995.

44. Zelle S, Zantop T, Schanz S and Petersen W: Arthroscopic techniques for the fixation of a three-dimensional scaffold for autologous chondrocyte transplantation: Structural properties in an in vitro model. Arthroscopy 23: 1073-1078, 2007.

45. Dørum IH,Heir S, Solheim E and Magnussen LH: Implementation of conservative treatment prior to arthroscopic subacromial decompression of the shoulder. Knee Surg Sports Traumatol Arthrosc 25: 2060-2066, 2017.

46. Galle SE, Beck JD, Burchette RJ and Harness NG: Outcomes of elbow arthroscopic osteocapsular arthroplasty. J Hand Surg Am 41: 184-191, 2016

47. Hao J, Xu Z and Zhao Z: Ulnar impaction syndrome: Managed by wrist arthroscopy. Indian J Orthop 50: 172-176, 2016.

48. Kubo T, Utsunomiya H, Watanuki M, Hayashi H, Sakai A and Uchida S: Hip arthroscopic osteochondral autologous transplantation for treating osteochondritis dissecans of the femoral head. Arthrose Tech 4: e675-e680,2015.

49. Fosco M and Dagher E: Proposal of a therapeutic protocol for selected patients with patellofemoral knee osteoarthritis: Arthroscopic lateral retinacular release followed by viscosupplementation. Musculoskelet Surg 100: 171-178, 2016.

50. Colcuc C, Fischer S, Colcuc S, Busse D, Bliemel C, Neun O, Abt HP and Hoffmann R: Treatment strategies for partial chronic instability of the distal syndesmosis: An arthroscopic grading scale and operative staging concept. Arch Orthop Trauma Surg 136: 157-163, 2016.

51. Kim SJ, Jo SB, Kim TW, Chang JH, Choi HS and Oh KS: A modified arthroscopic anterior cruciate ligament double-bundle reconstruction technique with autogenous quadriceps tendon graft: Remnant-preserving technique. Arch Orthop Trauma Surg 129: 403-407, 2009.

52. Ahn JH, Lee YS and Ha HC: Anterior cruciate ligament reconstruction with preservation of remnant bundle using hamstring autograft: Technical note. Arch Orthop Trauma Surg 129: 1011-1015, 2009

53. Lee BI, Min KD, Choi HS, Kwon SW, Chun DI, Yun ES Lee DW, Jin SY and Yoo JH: Immunohistochemical study of mechanoreceptors in the tibial remnant of the ruptured anterior cruciate ligament in human knees. Knee Surg Sports Traumatol Arthrosc 17: 1095-1101, 2009.

54. Ochi M, Adachi N, Uchio Y, Deie M, Kumahashi N, Ishikawa M and Sera S: A minimum 2-year follow-up after selective anteromedial or posterolateral bundle anterior cruciate ligament reconstruction. Arthroscopy 25: 117-122, 2009.

55. Lee JH, Bae DK, Song SJ, Cho SM and Yoon KH: Comparison of clinical results and second-look arthroscopy findings after arthroscopic anterior cruciate ligament reconstruction using 3 different types of grafts. Arthroscopy 26: 41-49, 2010.

56. Morey VM, Nag HL, Chowdhury B, Pannu CD, Meena S, Kumar K and Palaniswamy A: Arthroscopic anatomic double bundle anterior cruciate ligament reconstruction: Our experience with follow-up of 4 years. J Clin Orthop Trauma 7: 17-22, 2016.

57. Morey VM, Nag HL, Chowdhury B, Sankineani SR and Naranje SM: A prospective comparative study of clinical and functional outcomes between anatomic double bundle and single bundle hamstring grafts for arthroscopic anterior cruciate ligament reconstruction. Int J Surg 21: 162-167, 2015.

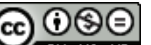

This work is licensed under a Creative Commons Attribution-NonCommercial-NoDerivatives 4.0 International (CC BY-NC-ND 4.0) License. 